\title{
Determinação estrutural dos metabólitos secundários presentes no fruto da Schinus terenbithifolius Raddi e avaliação da atividade anticolinesterásica
}

\author{
Larissa Mimares Carneiro Souza ${ }^{1}$; Alexsandro Branco ${ }^{2}$; Lissandra Carolina \\ Albuquerque $\operatorname{Reis}^{3}$ e Calila Teixeira Santos ${ }^{4}$ \\ 1. Bolsista PIBIC/CNPq, Graduanda em Farmácia, Universidade Estadual de Feira de Santana, e-mail: \\ larissamimarescs@gmail.com \\ 2. Orientador, Departamento de Saúde, Universidade Estadual de Feira de Santana, e-mail: branco@uefs.br \\ 3. Participante do projeto, Graduanda em Farmácia, Universidade Estadual de Feira de Santana, e-mail: \\ reislissa@gmail.com \\ 4. Participante do projeto, Universidade Estadual de Feira de Santana, e-mail: cal.tsantos@ gmail.com
}

PALAVRAS-CHAVE: Schinus terebinthifolius Raddi; Antioxidante; Acetilcolinesterase.

\section{INTRODUÇÃO}

O Brasil é um país mundialmente conhecido pela sua biodiversidade no que se refere ao bioma, entretanto esse ecossistema ainda é pouco estudado principalmente no que se refere ao nosso semiárido. De acordo com Moreira (2011), no Brasil há uma ampla variedade de frutos tropicais, nativos e exóticos que oferece muitas possibilidades de exploração econômica, especialmente para as regiões Norte e Nordeste do Brasil. Dentre esses frutos podemos destacar o gênero Schinus pertencente à família Anacardiaceae que do ponto de vista fitoquímico apresentam frutos com uma grande riqueza de metabólitos secundários com importantes atividades biológicas.

A aroeira-vermelha (Schinus terebinthifolius Raddi) ocorre de forma natural na Argentina, Paraguai, Uruguai, além de ser uma espécie também nativa do Brasil encontrada em todo o território nacional, sendo o seu fruto popularmente conhecido como pimenta rosa. Essa planta nativa é considerada pela medicina popular como adstringente, antidiarreica, anti-inflamatória, depurativa, diurética e febrífuga. Estudos fitoquímicos demonstram a presença de várias classes de compostos nesta espécie, tais como: taninos, saponinas, alcaloides, biflavonoides e ácidos triterpênicos. A descoberta do potencial antioxidante da Aroeira-vermelha intensificou as pesquisas e o uso desta espécie como princípios ativos em cosméticos e aditivos alimentares com o objetivo de aumentar a vida de prateleira de produtos ou mesmo prevenir o envelhecimento precoce.

Diante da riqueza de metabólitos secundários presentes na Schinus terebinthifolius Raddi, bem como as inúmeras atividades biológicas que a mesma possui, tornam-se importante o seu estudo no que concerne a avaliação da atividade anticolinesterásica, pois essa espécie pode vir a se tornar uma alternativa futura de tratamento de doenças degenerativas. Nossa proposta é investigar melhor esse campo de estudo já que ainda não se tem dados na literatura mostrando a realização destes testes nessa planta.

\section{MATERIAL E MÉTODOS OU METODOLOGIA (ou equivalente)}

O extrato bruto foi elaborado com $1 \mathrm{~kg}$ do material moído em moinho de facas, extraídos por maceração em etanol P.A $96 \%(1500 \mathrm{~mL})$, por 72 horas à temperatura ambiente $\left(25^{\circ} \mathrm{C}\right)$. Este foi fracionado por cromatografia em coluna aberta (CC) e eluído com misturas de solventes em ordem crescente de polaridade. Das 67 amostras obtidas, após serem unidas restaram 22 que foram analisadas utilizando técnicas espectroscópicas e espectrométricas como as técnicas de RMN (Ressonância Magnética 
Nuclear) de ${ }^{1} \mathrm{H}$ e ${ }^{13} \mathrm{C}$ uni e bidimensional, EM (Espectrometria de Massas) e UV-VIS (Ultravioleta Visível).

A atividade anticolinesterásica: A enzima utilizada será a acetilcolinesterase (AChE) de Electrophorus electricustipo VI (sigma). Em cada posso das microplacas (96 poços) serão adicionados $25 \mu \mathrm{L}$ de iodeto de acetilcolina $15 \mathrm{mM}, 125 \mu \mathrm{L}$ de DTNB, 50 $\mu \mathrm{L}$ de tampão Tris- $\mathrm{HCl} 50 \mathrm{mM}$ pH 8,0, contendo 0,1\% de BSA (Albumina do Soro Bovino) e $25 \mu \mathrm{L}$ da fração de alcaloide obtida de Schinus terenbinthifolus Raddi em diferentes concentrações. A absorbância será medida a $405 \mathrm{~nm}$ em leitor de microplaca a cada $13 \mathrm{~s}$ por 5 vezes. Em seguida serão adicionados $25 \mu \mathrm{L}$ da enzima $(0,22 \mathrm{U} / \mathrm{mL})$, e a absorbância será medida novamente a cada 13 segundos por 8 vezes.

\section{RESULTADOS E/OU DISCUSSÃO (ou Análise e discussão dos resultados)}

O cromatograma obtido por CLAE-DAD a partir do extrato dos frutos de $S$. terenbinthifolus apresentou como composto majoritário, um pico com $\operatorname{Tr} 48,27 \mathrm{~min}$, contendo espectro de UV com duas bandas de absorção, apresentando $\lambda_{\text {máx }}$ em 273 e $335 \mathrm{~nm}$. Este perfil de absorção indica a presença de um flavonoide, como composto majoritário, por apresentar duas bandas de absorção característica na região de 240-400 $\mathrm{nm}$. Dados da literatura indicam a presença de biflavonoides nesta espécie. Dentre eles, a amentoflavona e agastiflavona, que possuem espectro de UV correspondente ao composto predominante encontrado, o que sugere a presença deste composto no extrato dos frutos da aroeira vermelha (pimenta rosa) em estudo. Outros compostos fenólicos minoritários encontram-se no extrato, porém não possuem espectro de UV típicos que possibilitem sugerir a classe desses metabolitos.

A partir dos resultados obtidos acima o extrato bruto foi submetido à $\mathrm{CC}$ aberta resultando 65 frações. Após análise de camada delgada resultando 22 frações, estas foram analisadas por CLAE-DAD em. e CG-EM. e algumas frações foram selecionadas e submetidas à análise de RMN.

A Fração 2 apresentou uma coloração azul e foi encaminhada para o CG-EM e RMN para identificação. Na análise por CG-EM apresentou-se com um pico majoritário com $\operatorname{Tr}$ de 22.5 min., representando $65.46 \%$ da amostra. O espectro de massas desse composto revelou os fragmentos com $\mathrm{m} / z$ em $137 ; 95 ; 81 ; 69 ; 55$ e 41, indicando tratarse do composto esqualeno, conforme dados registrados na literatura (Sun et al., 2005; Oyugi et al., 2011). Esse resultado foi confirmado com as análises de RMN de $1 \mathrm{H}$ e DEPTQ 135 que permitiram a identificação deste composto. Após a atribuição dos valores aos átomos de carbono e hidrogênio à estrutura do composto e comparação com dados da literatura foi possível confirmar a substância como esqualeno.

O esqualeno é um triterpeno poli-insaturado contendo seis unidades de isopreno e é um precursor bioquímico do colesterol e outros esteroides (REDDY; COUVREUR, 2009), sendo também um intermediário chave na produção de diversos triterpenoídes em plantas, bactérias e fungos (SPANOVA; DAUM, 2011). Algumas plantas também acumulam o esqualeno como produto final, já que este pode ser liberado como composto volátil, agindo na defesa contra insetos ou atração de polinizadores (JIANG et al., 2015).

As frações 6-7 formaram um precipitado branco. Ao serem submetidos a analise em CCD observamos bandas características de terpenoides. Analisando-se a camada delgada das frações podemos observar que a Fração 7 e 6 possuem o mesmo Rf. As mesmas foram encaminhadas para analise em RMN. A análise dos dados de RMN $1 \mathrm{H}$ e de $13 \mathrm{C}$ e a comparação destes com a literatura (Morais et al, 2014)) permitiu a identificação em mistura do Ácido Masticadienoico (Z); Ácido Masticadienoico (E); Ácido Masticadienoico (Schinol). 
Após análise por CCD e CLAE-DAD, as frações de 20 a 38 foram unidas, pois apresentaram o perfil de dois dos biflavonoides comum a Schinus terenbithifolius Raddi (Amentoflavona e Agatisflavona). As frações unidas foram submetidas a purificação em coluna de Sephadex LH20, obtendo-se 20 frações. As frações com Rf semelhantes em análise por CCD foram agrupadas. Estas também foram submetidas a análise por CLAE-DAD, onde se comparou a fração SF11-14 com o padrão Agatisflavona, e confirmou-se realmente que se tratava deste biflavonoide.

A fração SF 18 a 20 foi submetida a análise em RMN 1H e observou-se duas manchas uma com o Rf da agatisflavona e uma outra, que possivelmente se tratava de outro biflavonoide amentoflavona, estas frações estão em processo de purificação em Sephadex LH 20 para possível isolamento e identificação posterior. O espectro de RMN de $1 \mathrm{H}$ desta substância apresentou sinais característicos de duas unidades flavonóidicas. Assim, a substância foi identificada como agatisflavona.

No cromatograma da fração 59, pode observar um pico bastante intenso no tempo de retenção em 9,22 minutos, possuem bandas de absorção máxima em torno de 216,4 e $271,6 \mathrm{~nm}$. Através desses resultados pode-se concluir que apresenta as características de absorção de ácidos fenólicos, com bandas em 190-220 e 260-280 nm (MICHELYN, 2008; OLESZEK E BIALY, 2006). Para elucidação da mesma injetamos o padrão de ácido gálico (Sigma) no mesmo método. Ao compararmos os tempos e retenção e espectos de UV podemos inferir que o pico majoritário da fração 59 trata-se do ácido gálico.

A avaliação quantitativa da inibição da acetilcolinesterase foi realizada pelo método de Ellman. Na concentração de $1 \mathrm{mg} / \mathrm{ml}$ testada, o padrão Eserina inibiu em 95,3\% a acetilcolinesterase, enquanto que o extrato bruto da Schinus terenbithifolius Raddi, enquanto que o extrato bruto inibiu 60, 38\%, na qual consideramos como uma potente inibição frente a acetilcolinesterase.

\section{CONSIDERAÇÕES FINAIS (ou Conclusão)}

Nas análises espectroscópicas foi possível obter cinco frações de Schinus terenbithifolius Raddi, no qual foi possível identificar os seguintes compostos: esqualeno, mistura de ácido graxo, agastiflavona, ácido gálico, e uma fração contendo uma mistura de triterpenos [Ácido Masticadienoico (Z); Ácido Masticadienoico (E); Ácido Masticadienoico (Schinol)]. Diante da diversidade de metabólitos secundários presentes em Schinus terebinthifolius Raddi, bem como as inúmeras atividades biológicas que a mesma possui, tornam-se importante o seu estudo no que concerne a avaliação da atividade anticolinesterásica, pois essa espécie pode vir a se tornar uma alternativa futura de tratamento de doenças degenerativas.

\section{REFERÊNCIAS}

JIANG, Y. et al. Volatile squalene from a nonseed plant Selaginella moellendorffii: Emission and biosynthesis. Plant Physiology and Biochemistry, v. 96, p. 1-8, 2015.

\section{MICHELIN, D. C. Estudo Químico-Farmacológico de Operculina macrocarpa L.}

Urb. (Convolvulaceae). Tese de Doutorado apresentada a Faculdade de Ciências Farmacêuticas, UNESP, 144 páginas, 2008.

MOREIRA, A. C. C. G. Caracterização de frutos de genótipo de cajá- umbuzeiras: teor de fitoquímicos bioativos e potencial antioxidante. Dissertação (Mestrado). Universidade Federal Rural de Pernambuco, 2011. 
REDDY, L. H.; COUVREUR, P. Squalene: A natural triterpene for use in disease management and therapy. Advanced Drug Delivery Reviews, v. 61, n. 15, p. 14121426, 2009.

SPANOVA, M.; DAUM, G. Squalene-biochemistry, molecular biology, process biotechnology, and applications. European Journal of Lipid Science and Technology, v. 113, n. 11, p. 1299-1320, 2011.

SUN, S. et al. The combination effects of phenolic compounds and fluconazole on the formation of ergosterol in Candida albicans determined by high-performance liquid chromatography/tandem mass spectrometry. Analytical biochemistry, v. 336, n. 1, p. 39-45, 2005.

OLESZEK, W. E BIALY, Z. Chromatographic determination of plants saponins - An update (2002-2005). J. Chromat. A, 1112(1-2): 78-79, 2006.

OYUGI, D. A. et al. Biological activity and mass spectrometric analysis of Vernonia amygdalina fractions. Journal of Bioscience and Technology, v. 2, n. 3, p. 287-304, 2011. 